\title{
LEVANTAMENTO E CARACTERIZAÇÃO DAS VARIÁVEIS UTILIZADAS EM ESTUDOS SOBRE ARBORIZAÇÃO URBANA
}

Giseli Silva Oliveira ${ }^{1}$; Antonio Alves Tavares²

\section{RESUMO}

A arborização urbana é um fator que vem sendo levado cada vez mais em conta no que diz respeito a pesquisas sobre a qualidade de vida nas cidades. Nesse sentido, vários trabalhos são realizados visando avaliar a arborização urbana em várias cidades brasileiras. O presente estudo teve por objetivo contribuir para a padronização desses trabalhos, fornecendo uma listagem e a caracterização das variáveis mais importantes utilizadas em pesquisas sobre arborização urbana, extraídas de diferentes publicações. O mesmo contribuirá ainda de forma significativa para a realização de pesquisas com o referido tema

Palavras-chave: Árvores - Diagnóstico da arborização - Planejamento urbano

\section{SURVEY AND CHARACTERIZATION OF THE VARIABLES USED IN URBAN FORESTRY STUDIES}

\section{ABSTRACT}

The urban forestry is a factor that is being taken more into account with regard to research on the life quality in urban centers. Accordingly, several studies are conducted to evaluate the urban forests in several Brazilian cities. This study aimed to contribute for the standartization of such works, listing and describing the more important variables used in urban forestry research, extracted from various publications. This study can contribute significatively to future research in this theme.

Key-words: Trees, Urban forest diagnosis, Urban planning

\footnotetext{
${ }^{1}$ Graduanda em Ciências Biológicas, Universidade Federal do Piauí - UFPI, Campus Ministro Reis Velloso. Email: gi19.phb@hotmail.com ${ }^{2}$ Engenheiro Agrônomo, Prof.Dr. Universidade Federal do Piauí -Campus Ministro Reis Velloso. Email: antonioalvestavares@yahoo.com.br
} 


\section{INTRODUÇÃO}

O crescimento desordenado das cidades brasileiras e as conseqüências geradas pela falta de planejamento urbano despertaram a atenção de planejadores no sentido de se perceber a vegetação como componente necessário ao espaço urbano (RIBEIRO, 2009).

Entende-se por arborização urbana o conjunto de terras públicas e privadas, com vegetação predominantemente arbórea que uma cidade apresenta em áreas particulares, praças, parques e vias públicas (SANCHOTENE, 1994). Já para Gonçalves (2000), o conceito de arborização urbana tem dado lugar a um conceito mais abrangente, é a nova área do saber denominada "silvicultura urbana", por se entender que os agrupamentos de árvores são mais significativos que árvores isoladas.

Segundo Dantas \& Souza (2004), trata-se de um assunto que vem merecendo uma atenção cada vez maior em função dos benefícios e até mesmo dos problemas que se apresentam em função da presença da árvore no contexto da cidade. O projeto urbano, ao estruturar a cidade e suas parcelas, maneja os componentes da paisagem construída entre e eles o elemento vegetal.

Um dos problemas referentes à arborização de vias públicas sem a realização de um prévio planejamento é o plantio de espécies de grande porte em lugares inadequados. Este procedimento é muito comum nas cidades brasileiras, causando, muitas vezes, sérios prejuízos, como rompimento de fios de alta-tensão, interrupções no fornecimento de energia elétrica, entupimento em redes de esgoto, obstáculos para circulação e acidentes envolvendo pedestres, veículos ou edificações (TAKAHASHI, 1992).

No que diz respeito aos aspectos ambientais, as árvores urbanas exercem influência direta sobre os microclimas, diminuição da radiação solar, temperatura, velocidade e direção dos ventos, além de, através da fotossíntese atuarem na purificação do ar (MASCARÓ \& MASCARÓ, 2005).
A história da arborização no Brasil ainda é recente, porém se observa uma grande preocupação em encontrar as árvores que se compatibilizem melhor às condições urbanas, quanto a aspectos estruturais, fisiológicos e ambientais, para que se assegure sucesso quanto ao plantio ao longo das vias (HOEHENE, 1944 citado por SANTOS \& TEIXEIRA, 2001).

O planejamento da arborização urbana deve considerar os elementos da infra-estrutura (rede de água, esgoto e rede elétrica), além do espaço físico (tráfego, largura de ruas, tipo de solo e características ambientais) e da análise da vegetação da região (COELBA, 2002).

Para Biondi \& Reissmann (1997), os parâmetros utilizados para a avaliação das árvores urbanas são ainda bastante subjetivos, pois os critérios utilizados transcendem valores quantitativos e qualitativos, porque os valores estéticos são bem maiores e bem mais difíceis de quantificar.

Segundo Coletto \& Müller (2008), planejar a arborização é indispensável para o desenvolvimento urbano e requer, antes de qualquer coisa, o conhecimento da situação existente, através de um inventário quali-quantitativo, assim como o conhecimento das características dos vegetais que poderão ser utilizados.

Portanto, para a montagem de um inventário qualiquantitativo da arborização urbana em uma determinada área, torna-se necessário o levantamento de todas as variáveis que devem ser observadas durante o estudo, bem como a forma como as mesmas serão avaliadas. Nesse contexto, a literatura se faz precária no que diz respeito à padronização de parâmetros para estudos no assunto. Assim, visando incentivar e facilitar o desenvolvimento de trabalhos sobre esse tema, o presente trabalho reúne e caracteriza, de forma geral e simplificada, as variáveis utilizadas na execução de diferentes trabalhos sobre arborização urbana. 


\section{MATERIAIS E MÉTODOS}

Para o levantamento das variáveis foi realizada uma revisão de literatura em publicações sobre arborização urbana no Brasil.

\section{RESULTADOS E DISCUSSÃO}

Com as informações obtidas pela análise de trinta publicações sobre arborização urbana no Brasil, obtevese um total de trinta e sete variáveis (Tabela 1), organizadas em seis grupos, onde as classificamos de acordo com o objetivo de cada trabalho. A tabela 1 traz ainda a freqüência com que essas variáveis foram encontradas durante a análise.

- Estudos de mapeamento e localização, com quatro variáveis que fornecem informações sobre a localização da árvore no espaço urbano.

- Estudos sobre aspectos intrínsecos, contendo seis variáveis que analisam aspectos estruturais e ecológicos das árvores;

- Estudos sobre aspectos florísticos, com quatro variáveis.

- Estudos sobre as relações entre as árvores e os equipamentos urbanos, com nove variáveis a partir das quais é possível obter informações sobre a forma como as árvores estão inseridas no meio urbano, no que diz respeito à existência ou não de conflitos.

- Estudos de quantificação e mensuração, com onze variáveis pelas quais se obtêm informações quantitativas da arborização em determinada área;

- Estudos fisiológicos, com três variáveis pelas quais é possível observar o vigor da árvore e sua utilidade para fins comerciais.
Para caracterização dessas variáveis, observou-se a forma como os resultados nos artigos foram interpretados pelos respectivos autores. A partir daí foi possível criar uma lista com informações sobre cada variável.

\section{Caracterização das Variáveis}

- Mapeamento e localização

1. Coordenadas geográficas (COLLETO et al., 2008; CRUZ et al, 2008; KURIHARA et al, 2005) - são obtidas por intermédio de GPS

2. Lado da rua (COLLETO et al., 2008; TEIXEIRA, 1999) - direito ou esquerdo, baseando-se no sentido centro - periferia, da cidade.

3. Número do imóvel (BORTOLETO et al., 2007; COLLETO et al., 2008; RODOLFO JÚNIOR et al., 2008) - número atribuído à edificação mais próxima da árvore.

4. Nome da rua (BORTOLETO et al., 2007; COELBA, 2002; COLLETO et al., 2008; CORRÊA, 2006; CRUZ et al., 2008; FARIA et al., 2007; GONÇALVES \& ROCHA, 2003; LIRA FILHO et al., 2005; RODOLFO JÚNIOR et al., 2008; SILVA FILHO et al., 2002; SILVA \& HASSE et al., 2008; TEIXEIRA, 1999; VOLPE-FILIKI et al., 2007) - denominação atribuída à via, normalmente, de conhecimento geral. 
Tabela 1: Classificação e freqüência das variáveis encontradas na análise das publicações sobre arborização urbana no Brasil Table 1: Classification and frequency of variables found in the analysis of publications on urban trees in Brazil

\begin{tabular}{|c|c|c|}
\hline & & Frequência \\
\hline \multirow{4}{*}{ Mapeamento e Localização } & 1. $\quad$ Coordenadas geográficas & 03 \\
\hline & 2. Lado da rua & 02 \\
\hline & 3. Número do imóvel & 03 \\
\hline & 4. Nome da rua & 13 \\
\hline \multirow{6}{*}{ Aspectos intrínsecos } & 5. Desenvolvimento das raízes & 16 \\
\hline & 6. Ecologia & 01 \\
\hline & 7. $\quad$ Fenologia & 03 \\
\hline & 8. $\quad$ Fitossanidade & 12 \\
\hline & 9. $\quad$ Porte & 06 \\
\hline & 10. Status & 09 \\
\hline \multirow{4}{*}{ Aspectos florísticos } & 11. Identificação & 21 \\
\hline & 12. Porcentagem de espécies exóticas (florist) & 05 \\
\hline & 13. Porcentagem de espécies frutíferas (florist) & 03 \\
\hline & 14. Porcentagem de espécies nativas (florist) & 04 \\
\hline \multirow{9}{*}{$\begin{array}{c}\text { Relações entre árvores e equipamentos } \\
\text { urbanos }\end{array}$} & 15. Afastamento predial & 04 \\
\hline & 16. Altura da fiação & 06 \\
\hline & 17. Área do passeio & 06 \\
\hline & 18. Compatibilidade & 10 \\
\hline & 19. Distância entre árvore e meio-fio & 08 \\
\hline & 20. Largura e comprimento da via & 08 \\
\hline & 21. Proteção & 04 \\
\hline & 22. Tipo de fiação & 07 \\
\hline & 23. Tipo de poda & 10 \\
\hline \multirow{11}{*}{ Quantificação e mensuração } & 24. Altura da $1^{\text {a }}$ bifurcação & 10 \\
\hline & 25. Altura geral da copa & 16 \\
\hline & 26. Área foliar & 02 \\
\hline & 27. Área para espessamento do tronco & 07 \\
\hline & 28. Circunferência à altura do peito & 14 \\
\hline & 29. Densidade da arborização & 07 \\
\hline & 30. Diâmetro da copa & 12 \\
\hline & 31. Diâmetro na base da $1^{a}$ bifurcação & 01 \\
\hline & 32. Numeração dos espécimes & 04 \\
\hline & 33. Numero de covas & 01 \\
\hline & 34. Número de espécimes mortos & 04 \\
\hline \multirow{3}{*}{ Estudos fisiológicos } & 35. Análise química de nutrientes & 01 \\
\hline & 36. Cor das folhas & 01 \\
\hline & 37. Toxicidade & 01 \\
\hline
\end{tabular}


- Aspectos intrínsecos

5. Desenvolvimento das raízes (ALMEIDA \& RONDON NETO, 2010; COELBA, 2002; COLLETO et al., 2008; CRUZ et al., 2008; FARIA et al., 2007; GONÇALVES \& ROCHA, 2003; LIRA FILHO et al., 2005; LOBODA et al., 2005; MENESES et al., 2003 RODOLFO JÚNIOR et al., 2008; SILVA FILHO et al., 2002; SILVA et al., 2006; SILVA \& HASSE et al., 2008; SILVA et al., 2008; TEIXEIRA, 2009; VOLPE-FILIKI et al., 2007) - verifica a compatibilidade da raiz com a calçada. O ideal é que o crescimento do sistema radicular seja profundo, e não superficial.

6. Ecologia (SILVA FILHO et al., 2002) - relações entre a árvore e outras formas de vida de plantas (epífitas) ou outros seres vivos como pássaros, insetos, fungos.

7. Fenologia (KURIHARA et al., 2005; SILVA FILHO et al., 2002; VELASKI et al., 2008) - condição geral das folhas, flores e frutos. Períodos de floração, amadurecimento dos frutos e caducifolia.

8. Fitossanidade (BIONDI \& REISSMAN, 1997; CORRÊA, 2006; FARIA et al., 2007; GONÇALVES \& ROCHA, 2003; LIRA FILHO et al., 2005; RODOLFO JÚNIOR, 2008; SILVA FILHO et al., 2002; SILVA et al., 2006; SILVA et al., 2002; SILVA \& HASSE et al., 2008; VOLPE-FILIKI et al., 2007) - observa a sanidade da árvore no que diz respeito ao ataque de insetos, doenças ou injúrias mecânicas.

9. Porte (COELBA, 2002; LOBODA et al., 2005; MENESES et al., 2003; SILVA et al., 2002; TEIXEIRA, 1999; VELASKI et al., 2008) - altura geral da árvore: até $5 \mathrm{~m}$, pequeno porte; de 5 a $10 \mathrm{~m}$, médio porte e acima de $10 \mathrm{~m}$, grande porte (COELBA, 2002).

10. Status (AMARAL et al., 1996; COLLETO et al., 2008; GONÇALVES \& ROCHA, 2003; LIRA
FILHO et al., 2005; LOBODA et al., 2005; MICHI \& COUTO, 1996; RODOLFO JÚNIOR, 2008; SILVA FILHO et al., 2002; TEIXEIRA, 1999) - Condição geral da árvore: muda, jovem, morta ou cortada.

11. Identificação (BORTOLETO et al., 2007; COELBA, 2002; COLLETO et al., 2008; CORRÊA, 2006; CRUZ et al., 2008; DANTAS \& SOUZA, 2004; FARIA et al., 2007; GONÇALVES \& ROCHA, 2003; KURIHARA et al., 2005; LOBODA et al., 2005; MELO \& SEVERO, 2007; MICHI \& COUTO, 1996; ROCHA et al., 2004; RODOLFO JÚNIOR, 2008; SILVA et al., 2006; SILVA et al., 2002; SILVA \& HASSE et al., 2008; SILVA et al., 2008; TEIXEIRA, 1999) - Nome científico, convencionado pela comunidade botânica e nome vulgar adotado por populares, o qual pode variar de uma região para outra.

\section{- Aspectos florísticos}

12. Porcentagem de espécies exóticas (ALMEIDA \& RONDON NETO, 2010; COELBA, 2002; CORRÊA, 2006; DANTAS \& SOUZA, 2004; TEIXEIRA, 1999) - parcela de espécies presentes no local que não são típicas do país. Geralmente verifica-se a existência de conflitos entre essas espécies e as nativas.

13. Porcentagem de espécies frutíferas (ALMEIDA \& RONDON NETO, 2010; COELBA, 2002; CORRÊA, 2006; ROCHA et al., 2004) - parcela de espécies que produzem frutos comestíveis. Geralmente o que se observa é o tipo de fruto. Em vias de grande circulação não é recomendável que haja espécies que produzam frutos pesados, por causa do risco de acidentes;

14. Porcentagem de espécies nativas (ALMEIDA \& RONDON NETO, 2010; COELBA, 2002; CORRÊA, 2006; DANTAS \& SOUZA, 2004;) - parcela de espécies típicas do país. 
- Relações entre árvores e equipamentos urbanos

15. Afastamento predial (ALMEIDA \& RONDON NETO, 2010; COELBA, 2002; GONÇALVES \& ROCHA, 2003; LIRA FILHO et al., 2005) - analisa a possibilidade de conflito entre as construções ao redor da árvore e estruturas como galhos e raízes.

16. Altura da fiação (ALMEIDA \& RONDON NETO, 2010; COELBA, 2002; CRUZ et al., 2008; FARIA et al., 2007; LOBODA et al., 2005; SILVA et al 2006) os postes de energia medem em média de 9 a $12 \mathrm{~m}$ de altura. Contudo algumas espécies erroneamente plantadas acabam entrando em conflito inclusive com a fiação de alta tensão. Segundo a Coelba (2002), o ideal é que a copa da árvore fique a pelo menos $1 \mathrm{~m}$ abaixo da fiação telefônica que é a mais baixa, a 5,4m de altura.

17. Área do passeio (COELBA, 2002; COLLETO et al., 2008; MENESES et al., 2003; RODOLFO JÚNIOR et al, 2008; SILVA et al, 2006; SILVA \& HASSE et al., 2008) - espaço livre para a circulação de pedestres. Não deve haver interferência da árvore no mesmo.

18. Compatibilidade (COELBA, 2002; COLLETO et al., 2008; CORRÊA, 2006; MENESES et al., 2003; MICHI \& COUTO,1996; SILVA et al., 2002; SILVA FILHO et al., 2002; SILVA \& HASSE et al., 2008) Observa as relações entre arborização e os equipamentos do meio urbano (fiação, sinalização, calçadas, esgoto, monumentos e construções), no que diz respeito à existência ou não de conflitos entre eles.

19. Distância entre a árvore e o meio fio (ALMEIDA \& RONDON NETO, 2010; COELBA, 2002; CRUZ et al., 2008; GONÇALVES \& ROCHA, 2003; LOBODA et al., 2005; RODOLFO JÚNIOR et al., 2008; SILVA et al., 2006; SILVA et al., 2002) - não foi observado um padrão para essa variável, mas o ideal é que as árvores sejam plantadas a uma distância adequada do meio fio, que deve levar em conta crescimento lateral do sistema radicular.
20. Largura e comprimento da via (ALMEIDA \& RONDON NETO, 2010; COELBA, 2002; COLLETO et al., 2008; FARIA et al., 2007; MENESES et al., 2003; SILVA FILHO et al., 2002; SILVA et al., 2006; SILVA \& HASSE et al., 2008) esta variável está relacionada com a densidade da arborização, ou seja, observa, de acordo com a largura e comprimento da via, se a arborização está em excesso (ao ponto de existir conflitos entre espécimes), se é satisfatória ou se é insuficiente..

21. Proteção (COELBA, 2002; MICHI \& COUTO,1996; SILVA et al., 2002; TEIXEIRA, 1999) - geralmente utilizada em plantas jovens, para protegê-las do calor excessivo, animais, vandalismo, vento etc. São exemplos: gradil e tutor. O uso de manilhas não é adequado, pois não permitem o desenvolvimento natural do sistema radicular.

22. Tipo de fiação (COELBA, 2002; COLLETO, 2008; GONÇALVES \& ROCHA, 2003, ROCHA et al., 2004; RODOLFO JÚNIOR et al., 2008; SILVA FILHO et al., 2002; SILVA et al., 2008) - Ausente ou presente. Quando presente verifica-se a tensão (alta ou baixa) e a compatibilidade com a copa da árvore.

23. Tipo de poda (COELBA, 2002; CRUZ et al., 2008; FARIA et al., 2007; GONÇALVES \& ROCHA, 2003; ROCHA et al., 2004; RODOLFO JÚNIOR et al., 2008; SILVA \& HASSE et al., 2008; TEIXEIRA, 1999; VOLPE-FILIKI et al., 2007) o estudo dos artigos permitiu a identificação de quatro tipos de poda, caracterizados segundo os conceitos de Gilman \& Eisner, 200?.

o Poda de limpeza: remoção de galhos quebrados, doentes ou em conflito com equipamentos urbanos. Visa eliminar a possibilidade de acidentes futuros com galhos secos, bem como os focos de fungos ou pragas.

o Poda de elevação de copa: encurtamento regular dos galhos mais baixos, favorecendo o desenvolvimento dos galhos superiores. Favorece o aumento da área de passeio e evita conflitos com a fiação.

Giseli Silva Oliveira e Antonio Alves Tavares 
o Poda estrutural: o desenvolvimento de um único galho é favorecido em detrimento dos demais por encurtamento. Esse tipo de poda direciona o crescimento da planta tornando-a compatível com os equipamentos urbanos.

o Poda drástica: remoção excessiva, inadequada ou desnecessária de galhos. Geralmente esse tipo de poda deixa cicatrizes profundas na árvore que se torna susceptível a focos de fungos, bactérias e pragas.

\section{- Quantificação e mensuração}

24. Altura da $\mathbf{1}^{\text {a }}$ bifurcação (CRUZ et al., 2008; KURIHARA et al., 2005; LIRA FILHO et al., 2005; LOBODA et al., 2005; MENESES et al., 2003; SILVA et al., 2006; SILVA FILHO et al., 2002; SILVA \& HASSE et al., 2008; SILVA et al., 2008) por essa variável analisa-se a possibilidade de conflitos entre a arborização e pedestres e/ou carros. Em vias de grande movimentação pública, a primeira bifurcação das árvores deve seguir uma altura mínima de $1,8 \mathrm{~m}$.

25. Altura geral da copa (BORTOLETO et al., 2007; COELBA, 2002; COLLETO et al., 2008; FARIA et al., 2007; GONÇALVES \& ROCHA, 2003; KURIHARA et al., 2005; LIRA FILHO et al., 2005; LOBODA et al., 2005; MENESES et al., 2003; MICHI \& COUTO, 1996; ROCHA et al., 2004; RODOLFO JÚNIOR et al., 2008; SILVA et al., 2006; SILVA FILHO et al., 2002; SILVA \& HASSE et al., 2008; SILVA et al., 2008) - semelhante à $1^{\text {a }}$ variável, nesta também se verificam as possíveis interferências das copas das árvores em redes de fiação e segue os mesmos parâmetros já citados.

26. Área foliar (ADAMI et al., 2007; AMARAL et al., 1996; BIONDI \& REISSMAN, 1997; SEVERINO et al., 2010) - medições realizadas na folhas da árvore. Esse parâmetro está relacionado a processos físicos como evapotranspiração, captação de $\mathrm{CO}_{2}$, fluxo hídrico, luminosidade etc. Existem aparelhos específicos para esta atividade (AMARAL et al., 1996).

27. Área para o espessamento do tronco (COELBA, 2002; COLLETO et al., 2008; MENESES et al., 2003; SILVA et al., 2006; SILVA \& HASSE et al., 2008; TEIXEIRA, 1999; VOLPE-FILIKI et al., 2007) - espaço no entorno do tronco livre para o seu desenvolvimento, bem como para uma boa infiltração.

28. Circunferência à Altura do Peito (CAP) (ALMEIDA \& RONDON NETO, 2010; AMARAL et al., 1996; BIONDI \& REISSMAN, 1997; BORTOLETO et al., 2007; COLLETO et al., 2008; CRUZ et al., 2008; FARIA et al., 2007; GONÇALVES \& ROCHA, 2003; KURIHARA et al., 2005; MELO \& SEVERO, 2007; MICHI \& COUTO, 1996; ROCHA et al., 2004; SILVA et al., 2006) comumente confundida com DAP (Diâmetro à Base do Peito), esta é medida com paquímetro e aquela, com fita métrica. São medidas importantes no cálculo do volume ou crescimento da planta, que possui fórmulas específicas. Convencionalmente, essa medida é feita a $1,3 \mathrm{~m}$ do solo.

29. Densidade da arborização (COLLETO et al., 2008; CORRÊA et al., 2006; CRUZ et al., 2008; DANTAS \& SOUZA, 2004; GONÇALVES \& ROCHA, 2003; LOBODA et al., 2005; MICHI \& COUTO, 1996) determina a quantidade de árvores por $\mathrm{Km}^{2}$. O parâmetro varia de acordo com local e a extensão do mesmo.

30. Diâmetro da copa (ALMEIDA \& RONDON NETO, 2010; AMARAL et al., 1996; BIONDI \& REISSMAN, 1997; COELBA, 2002; FARIA et al., 2007; GONÇALVES \& ROCHA, 2003; LIRA FILHO et al., 2005; MENESES et al., 2003; ROCHA et al., 2004; VELASKI et al., 2008) - por esse parâmetro observa-se o sombreamento fornecido pela árvore, bem como a possibilidade de interferência da mesma em equipamentos urbanos como construções, sinais ou fiação. Geralmente é medida pela sombra projetada pela árvore. 
31. Diâmetro na base da primeira bifurcação (LOBODA et al., 2005) - é feita uma relação entre o diâmetro da base e os galhos da primeira bifurcação. Quanto maior o diâmetro da base, maior é a força de sustentação dos galhos. Nesse sentido também se observa o formato da bifurcação: V- maior possibilidade de quebrar ou U- menor possibilidade de quebrar (GILMAN \& EISNER, 200?).

32. Numeração dos espécimes (BORTOLETO et al., 2007; CRUZ et al., 2008; GONÇALVES \& ROCHA, 2003; KURIHARA et al., 2005) - é feita para facilitar a identificação de cada espécime.

33. Número de covas (BORTOLETO et al., 2007) quantidade de buracos abertos, nos quais ou será plantada uma árvore, ou deles foram retiradas. Neste último caso, verificam-se os motivos que levaram à retirada da planta.

34. Número de espécimes mortos (BORTOLETO et al., 2007) - Por esta variável pode-se obter informações a respeito de possíveis impactos como infestação de pragas, manutenção inadequada ou até vandalismo.

\section{- Estudos fisiológicos}

35. Análise química de nutrientes (BIONDI \& REISSMAN, 1997) - é realizada uma coleta de material vegetal (galhos, frutos e folhas) preferencialmente do topo da árvore, pois essa região está menos sujeita a sombreamentos das construções urbanas. A partir do material, é feita em laboratório a análise dos nutrientes presentes, assim é possível obter informações a respeito do vigor a árvore.

36. Cor das folhas (BIONDI \& REISSMAN, 1997) Variável específica de cada espécie que influenciada por fatores como clima ou período do ano. A coloração pode ser influenciada pela falta ou excesso de algum nutriente, por exemplo, o magnésio, que estando em falta provoca a clorose da folha.

37. Toxicidade (COELBA, 2002; SCHUCH, 2006) presença de princípios tóxicos que podem estar relacionados com a casca, com o látex, folhas ou flores da espécie (COELBA, 2002).

O planejamento da arborização urbana torna-se difícil com a subjetividade dos conceitos de avaliação e com a falta de compromisso na elaboração de projetos. Estes, muitas vezes, segundo Bortoleto, Silva Filho e Lima (2006), citados por Almeida e Barbosa, (2010) baseiam-se em métodos empíricos, desprovidos de um conhecimento real do assunto.

Atualmente existe uma ausência de padrões e critérios para avaliação das áreas verdes urbanas (ROSSETTI; PELLEGRINO \& TAVARES, 2010).

Paiva, (2009) afirma ainda que um planejamento adequado passa pelo pleno conhecimento das características qualiquantitativas da arborização urbana, para possibilitar a realização de intervenções com maiores chances de sucesso. Uma condição indispensável ao planejamento é a realização de um inventário da arborização, para servir de base à elaboração um diagnóstico da mesma.

Pelas considerações dos autores acima entendemos que não existe um conjunto padrão de variáveis que devem observadas nos estudos de arborização urbana. Percebemos que algumas variáveis são mais representativas, ou seja, foram encontradas com mais freqüência durante a análise das publicações. Por exemplo, as variáveis “4”, “5”, “8”, “11”, “18”, “23”, “24”, “25”, “28” е “30”. Cada pesquisador, de acordo com seus objetivos, escolhe e as padroniza de forma a obter as informações necessárias ao desenvolvimento de seu trabalho.

A tabela 2 traz as variáveis padronizadas por Silva Filho et al. (2002), baseados nos estudos de Thurman (1983) e Dalcin (1992a). Cada variável apresenta-se com as características que devem ser observadas em campo. Os referidos autores, além do diagnóstico, apresentam soluções para os problemas encontrados. Essa metodologia favoreceu o acervo de informações e permitiu uma melhor interpretação dos resultados. Porém, no campo “Ação recomendada”, os autores Giseli Silva Oliveira e Antonio Alves Tavares 
não levaram em conta os conceitos de poda, pois a denominação utilizada (poda leve ou pesada) não leva em consideração o tipo de estrutura a ser podada, por exemplo: diâmetro dos galhos, tipo de bifurcação (V ou U) e idade da árvore, por exemplo. Baseando-se apenas nessa tabela podem ser realizadas podas que prejudiquem a árvore.

A esse respeito, o Professor Edward Gilman Professor Edward Gilman do departamento de Hoticultura Sustentável da Universidade da Flórida, dedicou-se à elaboração de manuais que abordam os conceitos de poda, os quais se fazem acima dos padrões observados no Brasil.

Já a tabela 3, apresenta a planilha de coleta de dados sobre arborização urbana, padronizada por Lacerda et al. (2011). Trata-se de uma publicação relativamente nova, que propõe a observação de muitas outras variáveis não citadas anteriormente, no presente trabalho.

Tabela 2: Tabela de variáveis utilizadas em estudos sobre arborização urbana no Brasil

Table 2: Table of variables used in research on urban forestry in Brazil

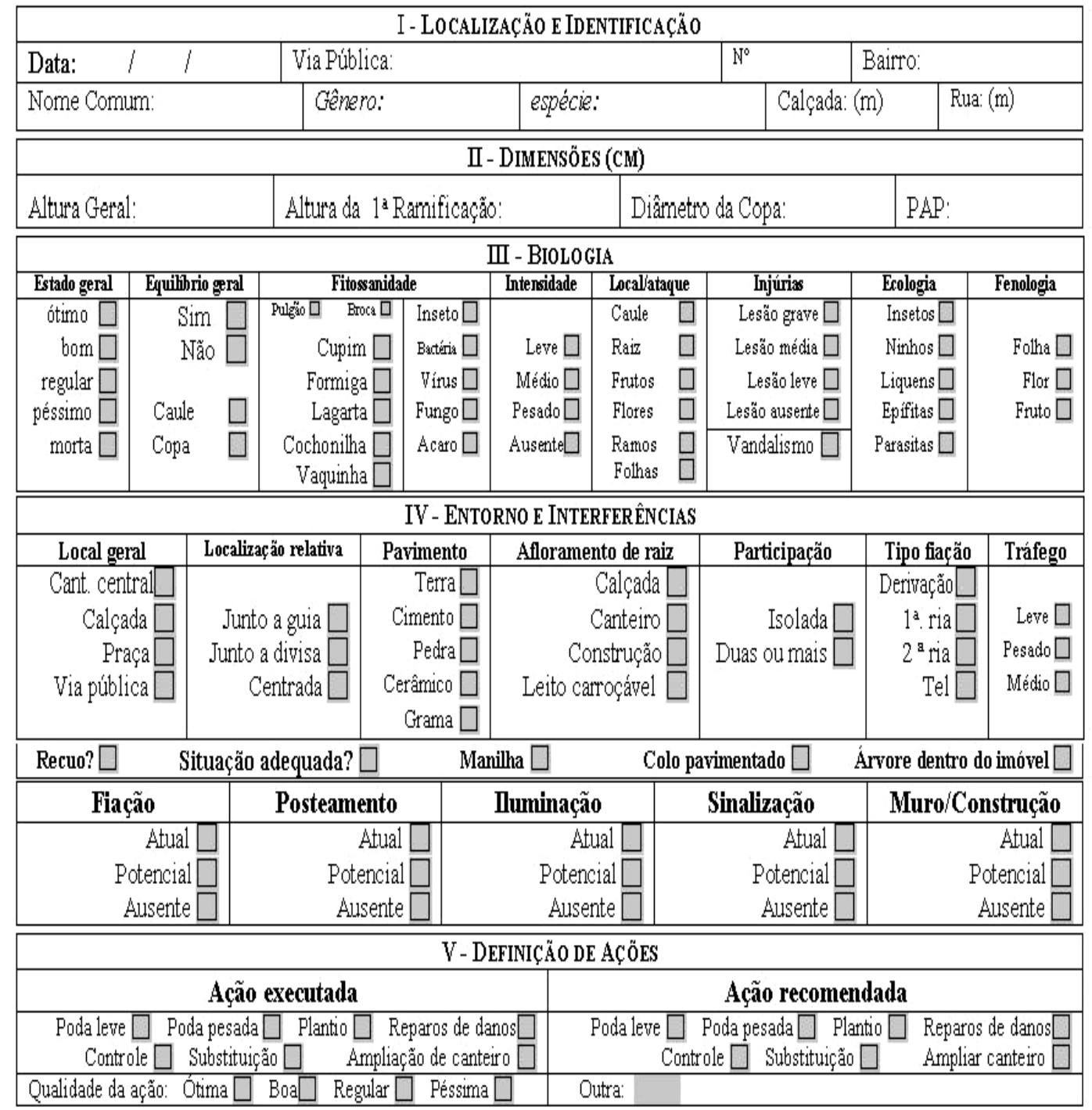

Silva Filho et al. (2002) 
Table 3: Planilha de coleta de dados sobre arborização urbana

Table 3: Data collection worksheet on urban forestry

Planilha para coleta de dados.

Fotos: () Árvore ( Tronco ()Ramo ()Flor ()Fruto

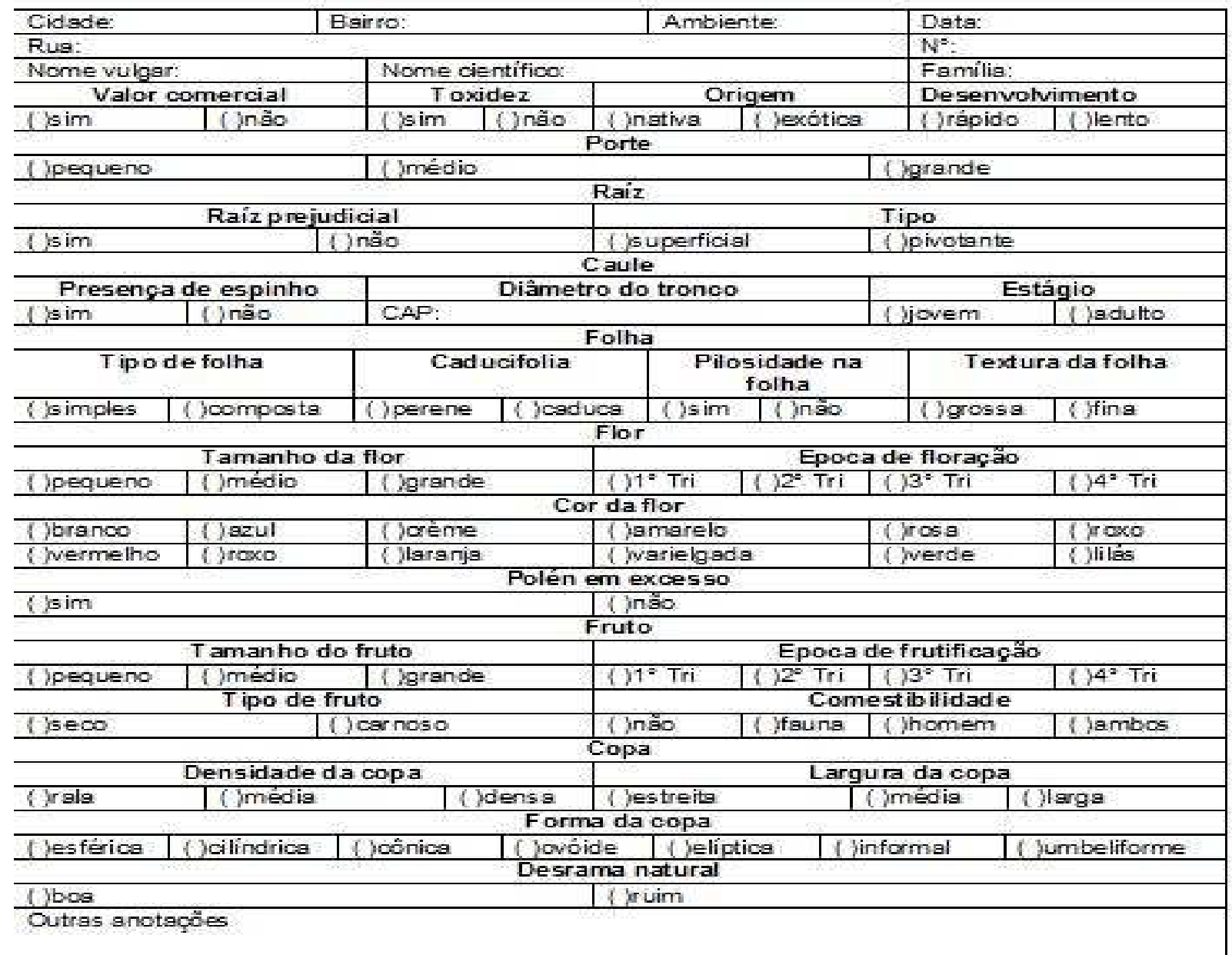

Lacerda et al. (2011)

Comparando as duas tabelas, notamos as diferenças quanto às variáveis observadas em campo, sugeridas por seus respectivos autores. As duas acabam por se complementar no conjunto de informações. Assim sugere-se a formulação de uma nova tabela que compreenda tanto as informações da tabela 2 quanto da tabela 3, o que aumentaria o acervo de informações e facilitaria a obtenção dos resultados, além de favorecer o desenvolvimento de vários tipos de trabalhos. 


\section{CONCLUSÃO}

A realização de todo e qualquer estudo científico exige o levantamento de parâmetros segundo os quais se obterão os resultados esperados. Para isso, é necessário que haja um vasto embasamento teórico, que normalmente é adquirido com pesquisas em artigos ou outras publicações relacionadas com o tema escolhido. Com os estudos sobre arborização urbana não é diferente, porém o que se observou na análise das publicações sobre arborização urbana no Brasil é que existe certa dificuldade em se padronizar as variáveis que serão utilizadas, o que provavelmente se deva à forma como as mesmas são abordadas na literatura específica, ou seja, não se encontra claramente definida a forma como devem ser utilizadas em campo ou como contribuirão para os resultados.

Nesse contexto, esperamos que a classificação e caracterização das variáveis constantes no presente trabalho possam contribuir de forma significativa para a elaboração de projetos e realização de pesquisas na referida área.

\section{REFERÊNCIAS BIBLIOGRÁFICAS}

ADAMI, M.; et al. Estimativa de Área Foliar de Soja Usando Imagens Digitais e Dimensões Foliares. In: SIMPÓSIO BRASILEIRO DE SENSORIAMENTO REMOTO, 8, 2007, Florianópolis-SC. Anais... Florianópolis: INPE, 2007. 6p.

AGUiRRE JUNiOR, J. H.; LIMA, A. L. M. P. Uso de Arvores e Arbustos em Cidades Brasileiras. Revista SBAU, Piracicaba, v.2, n.4, p. 50-66, dez. 2007.

ALMEIDA, D. N.; RONDON NETO, R. M. Análise da Arborização Urbana de Três Cidades da Região Norte do Estado de Mato Grosso. Acta Amazônica, v. 40, n. 4, p. 647-656, 2010.

ALVES, M. S.; GOUVEIA, V. V. Atitudes em Relação à Arborização Urbana: Uma Contribuição da Psicologia Ambiental para a Qualidade de Vida Urbana. Textos do Laboratório de Psicologia Ambiental, Universidade de Brasília, v.4, n.6, 1995.

AMARAL, S. et al. Relações entre Índice de Área Foliar (LAI), Área Basal e Índice de Vegetação (NDVI) em relação a diferentes estágios de crescimento secundário na Floresta Amazônica em Rondônia. In: SIMPÓSIO BRASILEIRO DE SENSORIAMENTO REMOTO, 8, 1996, Salvador-Ba. Anais... Salvador: INPE, 1996. 5p.

BIONDI, D.; REISSMAN, C. B. Avaliação do Vigor das Árvores Urbanas através de Parâmetros Quantitativos. Scientia Florestalis, n.52, p.17-28, dez. 1997.

BORTOLETO, S. et al. Composição e Distribuição da Arborização Viária da Estância de Águas de São Pedro-SP. Revista SBAU, Piracicaba, v.2, n.3, p. 32-46, 2007.

COELBA. Guia de Arborização Urbana. Diretoria de Gestão de Ativos; Departamento de Planejamento dos Investimentos; Unidade de Meio Ambiente. Bahia, 2002.

COLleto, E. P. MÜLlER, N. G.; WOLSKI, S. S. Diagnóstico da Arborização de Vias Públicas do Município de Sete de Setembro-RS. Revista SBAU, Piracicaba, v.3, n.2, p. 110-122, jun. 2008.

CORRÊA, L. R. Relações entre o Critério Socioeconômico e Parâmetros Ecológicos Relativos à Arborização Viária de Canoas, Brasil. Instituto Anchietano de Pesquisas. Pesquisas: Botânica. São Leopoldo, n. 57, p. 303-317, 2006.

CRUZ, P. M. F. et al. Análise Quali-Quantitativa da Arborização Urbana da Avenida Marechal Castelo Branco em TeresinaPiauí. In: CONGRESSO DE PESQUISA E INOVAÇÃO DA REDE NORTE NORDESTE DE EDUCAÇÃO TECNOLÓGICA, 3, 2008, Fortaleza-Ce. Anais... Fortaleza: CEFET, 2008. 8p.

DANTAS, I. C.; SOUZA, C. M. C. de. Arborização urbana na cidade de Campina Grande - PB: Inventário e suas espécies. Revista de Biologia e Ciências da Terra, v.4, n.2, 2004. 
FARIA, J. L. G.; MONTEIRO, E. A.; FISCH, S. T. V. Arborização de Vias Públicas do Município de Jacareí - SP. Revista SBAU, Piracicaba, v.2, n.4, p. 20-33, dez 2007.

GILMAN, E. F.; EISNER, N. J. Pruning shade trees in the landscape. Landscape Plants. Disponível em: <http// hort.ufl.edu/woody/> Acesso em 23 nov. 2010.

GONÇALVES, S.; ROCHA, F. T. Caracterização da Arborização Urbana do Bairro de Vila Maria Baixa. Conscientia e Saúde, São Paulo, ano 2, v.2, p. 67-75, 2003.

GONÇALVES, W. Florestas Urbanas. Revista Ação Ambiental, Ano 2, n.9, p.17-19, 2000.

KURIHARA, D. L.; IMAÑA-ENCINAS, J. PAULA, J. E. de. Levantamento da Arborização do Campus da Universidade de Brasília. Cerne, Lavras, v.11, n. 2, p. 127-136, abr./jun. 2005.

LACERDA, R. M. de A.; LIRA FILHO, J. A. de; SANTOS, R. V. dos. Indicação de Espécies de Porte Arbóreo para a Arborização Urbana no Semi-Árido Paraibano. Revista SBAU, Piracicaba, v.6, n.1, p.51-68, 2011.

LIRA FILHO, J. A. et al. Diagnóstico da Arborização Urbana do Bairro Bivar Olinto, na Cidade de Patos-PB. In: CONGRESSO BRASILEIRO DE ARBORIZAÇÃO URBANA, 10, 2005, Belo Horizonte/MG. Anais... Belo Horizonte: UFCG/DEF, 2005. 9p.

LOBODA, C. R. et al. Avaliação das Áreas Verdes em Espaços Públicos no Município de Guarapuava-PR. Ambiencia, Guarapuava, v.1, n.1, p.141-155, jan./jun. 2005.

MASCARÓ, L.; MASCARÓ, J. Vegetação Urbana. 2 ed. Porto Alegre: Mais Quatro Editora, 2005. 204 p.

MELO, E. F. R. Q.; SEVERO, B. M. A. Vegetação Arbórea do Campus da Universidade de Passo Fundo. Revista SBAU, Piracicaba, v.2, n.2, p. 76-87, 2007.

MENESES, C. H. S. G. et al. Análise da Arborização dos Bairros do Mirante e Vila Cabral na Cidade de Campina GrandePB. Revista de Biologia e Ciências da Terra, v. 3, n. 2, 2 semestre, 2003.

MICHI, S. M. P.; COUTO, H. T. Z. do. Estudo de Dois Métodos de Amostragem de Árvores de Rua na Cidade de Piracicaba. In: CURSO EM TREINAMENTO SOBRE PODAS EM ESPÉCIES ARBÓREAS FLORESTAIS E DE ARBORIZAÇÃO URBANA,1, 1996, Piracicaba-SP.

PAIVA, A. V. de. Aspectos da Arborização Urbana do Centro de Cosmópolis-SP. Revista SBAU, Piracicaba, v.4, n.4, p.1731, 2009.

RIBEIRO, F. A. B. S. Arborização Urbana em Uberlândia: Percepção da população. Revista da Católica, Uberlândia, v.1, n.1, p.224-237, 2009.

ROCHA, R. T. da; LELES, P. S. S.; NETO, S. N. O. Arborização de Vias Públicas em Nova Iguaçu, RJ: O Caso dos Bairros Rancho Novo e Centro. Revista Árvore, Viçosa-MG, v.28, n.4, p.599-607, 2004.

RODRIGUES, J. R. de; BARBOSA, C. G. Diagnóstico da Arborização Urbana da Cidade de Cacoal-RO. Revista SBAU. Piracicaba, v.5, n.1, p.61-81, 2010.

RODOLFO JUNIOR, F. et al. Análise da Arborização Urbana em Bairros da cidade de Pombal no Estado da Paraíba. Revista SBAU. Piracicaba, v.3, n.4, p.3-19, 2008.

ROSSETTI, A. I. N.; PELlegrinO, P. R. M.; TAVARES, A. R. As Árvores e suas Interfaces no Ambiente Urbano. Revista SBAU. Piracicaba, v.5, n.1, p.1-24, 2010.

SANCHOTENE, M. do C.C. Desenvolvimento e Perspectivas da Arborização Urbana no Brasil. In: CONGRESSO BRASILEIRO DE ARBORIZAÇÃO URBANA, 2, 1994. São Luís-MA. Anais... São Luís: SBAU, 1994. p.15-26.

SANTOS, N. Z. R.; TEIXEIRA, I. F. Arborização de vias públicas: Ambiente x Vegetação. Porto Alegre-RS: Instituto Souza Cruz, 2001. 135 p.

SCHUCH, M. I. S. Arborização Urbana: Uma Contribuição à Qualidade de Vida com Uso de Geotecnologias. 2006. 101f. Dissertação (Mestrado) - Centro de Ciências Rurais, Universidade Federal de Santa Maria, Santa Maria, 2006.

SEMINÁRIO NACIONAL DE DISTRIBUIÇÃO DE ENERGIA ELÉTRICA, 7, 2006, Belo Horizonte. Cadastramento da Arborização em Vias Públicas de Maringá-PR. Belo Horizonte, ago. 2006. 
SEVERINO, L. S. et al. Método para Medição da Área Foliar do Pinhão Manso. Disponível em: $<$ http//www.biodiesel.gov.br/> Acesso em 22: nov. 2010

SILVA, A. G. et al. Comparação de Três Métodos de Obtenção de Dados para Avaliação Quali-Quantitativa da Arborização Viária, em Belo Horizonte-MG. Revista SBAU, Piracicaba, v.1, n.1, p. 31-44, 2006.

SILVA, E. M. da. et al. Estudo da Arborização Urbana do bairro Mansour, na Cidade de Uberlândia-MG. Caminhos de Geografia, Uberlândia, n. 3, v. 5, p. 73-83, fev. 2002.

SILVA FILHO, D. F. et al. Banco de Dados Relacional para Cadastro, Avaliação e Manejo da Arborização em Vias Públicas. Revista Árvore, Viçosa-MG, v.26, n.5, p.629-642, Nov. 2002.

SILVA, L. M.; HASSE, I. et al. Inventário da Arborização em Duas vias de Mirópolis-PR. Revista SBAU, Piracicaba, v.3, n.1, p. 36-53, mar. 2008.

SILVA, L. M. et al. Arborização dos Bairros Pinheiros, Brasília e Bancários em Pato Branco-PR. Scientia Agraria, Curitiba, v.9, n.3, p.275-282, 2008.

TAKAHASHI, L. Y. Monitoramento e Informatização da Administração e Manejo da Arborização Urbana. In: CONGRESSO BRASILEIRO SOBRE ARBORIZAÇÃO URBANA, 1.,1992, Vitória. Anais... Vitória: PMV/SMMA, 1992. p. 119-124.

TEIXEIRA, I. F. Análise Qualitativa da Arborização de Ruas do Conjunto Habitacional Tencredo Neves, Santa Maria-RS. Ciência Florestal, Santa Maria, v.9, n.2, p.9-21, 1999.

TUDINI, O. G. A Arborização de Acompanhamento Viário e a Verticalização na Zona 7 de Maringá-PR. 2006. $149 f$. Dissertação (Mestrado) - Centro de Ciências Humanas, Letras e Artes, Universidade Estadual de Maringá, Maringá, 2006

VELASCO, G. N. Arborização Viária X Sistemas de Distribuição de Energia Elátrica: Avaliação dos Custos, Estudo das Podas e Levantamento de Problemas Fitotécnicos. 2003. 117f. Dissertação (Mestrado) - Escola Superior de Agricultura Luis de Queiroz, Piracicaba, 2003.

VELASKI, S.; CARVALHO, J. A. de; NUCCI, J. C. Árvores Frutíferas na Arborização de Calçadas do Bairro Santa Felicidade-Curitiba/PR e Seus Banefícios para a Sociedade. Geografia: Ensino \& Pesquisa, Santa Maria v. 12, p. 972-985, 2008.

VOLPE-FILIKI, A.; SILVA, L. F. da; LIMA, A. M. L. P. Avaliação da Arborização de Ruas do Bairro São Dimas na Cidade de Piracicaba/SP através de Parâmetros Qualitativos. Revista SBAU, Piracicaba, v.2, n.1, 2007. 